\title{
Median Vein
}

National Cancer Institute

\section{Source}

National Cancer Institute. Median Vein. NCI Thesaurus. Code C33072.

A vein originating in the thumb that ascends the forearm and branches into the median basilic and median cephalic veins at the elbow. 